NBER WORKING PAPER SERIES

\title{
ON THE NEED FOR FISCAL DISCIPLINE IN A UNION
}

Joshua Aizenman

Working Paper No. 4656

\section{NATIONAL BUREAU OF ECONOMIC RESEARCH 1050 Massachusetts Avenue \\ Cambridge, MA 02138 \\ February 1994}

I would like to thank Nissan Liviatan, Gian Maria Milesi-Ferretti, Ramon Marimon, Don Mathieson, Jurgan von Hagen and the participants of the Economics seminars at the Hebrew University, University of Mannheim, and the Research Department at the International Monetary Fund for useful comments. All errors, however, are mine. This paper is part of NBER's research program in International Finance and Macroeconomics. Any opinions expressed are those of the author and not those of the National Bureau of Economic Research. 
NBER Working Paper \#4656

February 1994

\title{
ON THE NEED FOR FISCAL DISCIPLINE IN A UNION
}

\begin{abstract}
This paper investigates the behavior of public debt in countries forming a union (as outlined, e.g., by the Maastricht treaty). We consider a federal union of states where the center has limited control over the spending patterns of the union members, and where the union members' behavior has repercussions for the future public debt. The public has preferences against higher public debt, and will oust high-debt administrations. Adverse shocks are shown to induce a regime switch from a cooperative outcome to limited cooperation, and from limited cooperation to the noncooperative outcome. While a transitory adverse shock calls for a higher public debt in the cooperative regime, the switch towands limited cooperation entails a drop in the public debt (relative to the cooperative desirable outcome). With limited cooperation further drops in income will call for a drop in public debt. If the adverse shock is powerful enough, sustaining limited cooperation may become unfeasible. A regime switch may yield nonlinearities, where the macroeconomic behavior is abruptly altered following the switch. Our model provides a tentative support for limits on public debt, needed to free the instrument of deficit financing for use in bad recessions.
\end{abstract}

Joshua Aizenman Economics Department Dartmouth College Hanover, NH 03755 and NBER 


\section{Introduction and Summary}

The ambitious agenda outlined in the Maastricht Treaty envisions the transformation of Western Europe into an economic union. According to the Treaty, the transition towards the union must be supported by a proper macroeconomic convergence of the various countries. ${ }^{1}$ Consequently, a significant literature has emerged addressing both the wisdom and the need for imposing these criteria. A contested issue is the degree that a tight fiscal harmonization is entailed by the Union, and the need to restrict the public debt/GDP ratios tolerated among the countries forming the Union. ${ }^{2}$ Obviously, this issue is of concern beyond Europe -- and faces any country that is a federation of local governments.

The purpose of this paper is to investigate the need for fiscal discipline for an economy where the center has limited control over the spending patterns of the union members, and where the union members' behavior has repercussions for the future public debt. In practice, most unions are characterized by such a structure, differing in the degree to which the center has control of the fiscal behavior of its members, and the degree to which the union members have the ability to roll over part of their expenditure to the center. A recent painful example of this phenomenon is the S\&L crisis in the USA, which illustrated that some of the

1 The "convergence criteria" states that a country can join the union if its inflation rate is not more than $1.5 \%$ higher than the three lowest inflation rates in the EMS, its long-term interest rate is not more than $2 \%$ higher than the average observed in the three low-inflation countries, it has not experienced a currency realignment in the two years preceding the entrance in the union, its government budget deficit in not higher than $3 \%$ of its GDP, and its public debt/GNP ratio is below $60 \%$.

2 For a review of this debate, see Wyplosz (1991) and De Grauwe (1993). 
transmission generating the over-expenditure is accomplished via financial intermediation. For example, provincial government may encourage (or overlook) the provision of credit by local banks to questionable local businesses against IOU notes. Upon the collapse of some of these businesses there is political pressure on the central government to bail out the local banks (and perhaps the local businesses). If the financing of this rescue is done by increasing the public debt, the ultimate risk undertaking and expansionary policy of local provinces (or states) determines the volume of the questionable credit. Occasionally, the weakness of the center is manifested directly in the excessive spending of provincial governments. In developing countries where the fiscal authorities are weak, the central bank frequently uses seigniorage to finance the bailing out, resulting in high inflation. Our paper ignores this possibility, and focuses instead on the case where the marginal financing is done by public debt. ${ }^{3}$

The modeling strategy of the paper is to focus on a generic model where there is an interaction between the center and the peripheries under conditions of limited monitoring. We refrain from modeling the institutional details that enable the opportunistic behavior of economic decision makers, as the reduced-form approach may encompass various economic structures. Consider an economy where the treasury is relatively weak, and where the fiscal decisions are the outcome of the behavior of several competing policy makers. We call the collective body, consisting of these policy makers, the administration. The decision makers represent various interest groups that compete for fiscal resources. These interest groups may be provincial governments in a country composed of several provinces, or states in a fiscal union, or any pressure groups seeking to promote their own agenda. The

3 See Aizenman (1993) for a study of soft budget constraints where the marginal finance is done by seigniorage. 
administration allocates the planned fiscal outlays among the decision makers. In the short-run policy makers may abuse their official budgets, entailing higher pubic debt. Overtime, such opportunistic behavior is detected and punished by removing the policy makers and the administration. The public has preferences against higher public debt (as it reduces the future fiscal resources available for the provision of public goods or for public investment). It uses the public debt as an indicator regarding the competence of the administration to restrain the various decision makers, and will oust high debt administrations. We do not model the public behavior directly. Instead, we are taking a reduced-form approach, where consumer's preferences are reflected by their voting pattern, ousting high public debt administrations. 4

Our economy is characterized by negative externalities akin to the common pool problem. 5 The ability of local policy makers to shift some of their expenditure to the common pool of public debt encourages them to overspend, as they will share only part of the burden of future taxes, while sharing fully the present benefits. The ultimate outcome of the resultant externalities is that a noncooperative regime

4 Our model can be extended to allow part of the tax revenue to be spent on the provision of a public good. Our results continue to hold as long as the policy makers have the ability to use fiscal resources to expand their own consumption.

5 On the interplay of these externalities in a common currency area see, e.g., Canzoneri (1989), Casella (1991) and Aizenman (1992). On coordination porblems in the macro context see, for example, Hamada (1976), Bryant (1985), Canzoneri and Gray (1985), Buiter and Marston (1985), Turnovsky, Basar and D'orey (1988), Rogoff (1989), Alesina and Drazen (1991), Cukierman (1992) and Tornell and Velasco (1992). For a survey of the literature on macroeconomic policies and politics see Persson and Tabellini (1990). 
yields excessive current spending and shortens the effective planning horizon of the policy makers. The administration has a control variable (the planned public debt) that determines the planned fiscal allocation to the decision makers. The administration sets policies that maximize the expected utility of the representative decision maker, subject to the constraints imposed by their behavior. The existence of adverse externalities implies that the administration should set policies that induce the individual decision makers to prefer the cooperative outcome. The problem is akin to the organization of an intertemporal cartel, where the cartel manager chooses a price that is consistent with the lack of opportunistic behavior.

Our model supports the notion that the macroeconomic equilibrium is characterized by the existence of several regimes: cooperative, limited cooperation, and noncooperative regimes. A Fully cooperative regime is supported if policies that maximize the expected utility of a representative decision maker lead to an outcome where none of the decision makers has the incentive to deviate. Otherwise, the administration will be forced to scale down the planned fiscal expenditure (and the resultant public debt) to the highest level that entails cooperation. We refer to the resultant outcome as limited cooperation. If the attainment of limited cooperation is not feasible, policy makers end up behaving opportunistically. This behavior entails maximizing their welfare while ignoring the resultant negative externalities, leading to the noncooperative regime.

Adverse shocks are shown to induce a regime switch from a cooperative outcome to limited cooperation. A large enough unfavorable disturbance induces a switch to the noncooperative outcome. While a transitory adverse shock calls for a higher public debt in the cooperative regime (in order to offset the transitory decline in income, thereby smoothing consumption), the switch towards limited cooperation entails a drop in the public debt (relative to the cooperative desirable outcome). The adverse shock encourages the opportunistic behavior by increasing 
the marginal evaluation of the benefits of extra resources (due to the principle of diminishing marginal utility) and by shortening the planning horizon of decision makers. A drop in public debt is needed to "police" the union, preventing the tendency to overspend and to end up with the noncooperative outcome.

When we are in the limited cooperation regime, the binding constraint determining the pattern of public debt and fiscal expenditure is the incentive constraint: preventing opportunistic behavior. This implies that with limited cooperation further drops in income will call for a drop in public debt, an outcome that does not occur in the cooperative regime. If the adverse shock is powerful enough, sustaining limited cooperation may become unfeasible. In these circumstances we end up in the noncooperative regime, where the behavior of the various decision makers shorten the effective horizon of all. Consequently, a regime switch resulting from adverse shocks may change the correlation among macroeconomic variables. In addition, it may yield nonlinearities, where the macroeconomic behavior is abruptly altered following the regime switch, which in turn will occur if the severity of adverse shocks reaches a certain threshold. Finally, our model provides a tentative support for limits on public debt, needed to free the instrument of deficit financing for use in bad recessions.

Before turning to the present paper, it is constructive to place it in its proper context within the existing literature. A recent contribution by Alesina and Darzen (1989) explained delays in stabilization in terms of a war of attrition between competing groups who behave noncooperatively. They focused on the timing of the switch from a noncooperative to a cooperative outcome. This paper serves to illuminate the conditions inducing the opposite shift -- switching the economy from a well-behaved regime where agents cooperate to a noncooperative outcome. This paper illustrates too that the menu of possible regimes is richer than the extremes of cooperative and noncooperative behavior, and that the regime switch 
has important implications for the continuity of and the correlation among macroeconomic variables.

Section 2 of the paper introduces the model. In section 3 we characterize the possible regimes, the conditions yielding a regime switch, and the resultant patterns of the correlation among macroeconomic shocks. Section 4 closes the paper with concluding remarks.

\section{The Model}

We review in this section the budget constraints, the political uncertainty, and the timing of events in the model.

\subsection{The planned budget}

The union is composed of $\mathrm{n}$ symmetric provinces (or states), each managed by a decision maker. The federal administration has access to fiscal revenue (T), which are equally divided among the states. The fiscal plan for period $t$ is guided by a budget. It specifies a planned fiscal allocation of $\bar{G}_{t ; i}$ to $n$ decision makers $(i=1, \ldots n)$. The allocation divides equally the tax revenue (denoted by $\mathrm{T}$ ), and finances the rest by issuing public debt, in the form of a one-period bond. We denote by $b_{t}^{p}$ and $b_{t}^{a}$ the planned and the actual sales of these bonds in period $t$. Thus:

$$
\text { (1) } \overline{\mathrm{G}}_{\mathrm{t}, \mathrm{i}}=\frac{\mathrm{T}_{\mathrm{t}}+\mathrm{b}_{\mathrm{t}}^{\mathrm{p}}-(1+\mathrm{r}) \mathrm{b}_{\mathrm{t}-1}^{\mathrm{a}}}{\mathrm{n}} \text {. }
$$

where $r$ is the real interest rate, assumed to be exogenously given. The tax rate is denoted by $\tau$, the GNP by $Y$, so that $T=\tau Y$. To focus on the role of the public debt, we assume that the tax rate and output are exogenously given, and that the only control variable available to the administration is the planned sales of bonds, $b_{t}^{p}$. 


\subsection{Budget constraints and the political uncertainty}

The actual behavior of policy makers may diverge from the planned budget. Within each period there is limited monitoring of the actual activities of the decision maker. Each of them has a degree of flexibility in dictating the effective resources allocated to him from the center, so that the realized budget constraint facing a decision maker (assuming that he is not detected) is given by:

(2) $\quad \mathrm{G}_{\mathrm{t}, \mathrm{i}}=\overline{\mathrm{G}}_{\mathrm{t}, \mathrm{i}}+\mathrm{C}_{\mathrm{t}, \mathrm{i}}^{\mathrm{i}}$

where $C_{l, i}^{0}$ measures the opportunistic consumption of decision maker $i$. The limited monitoring is manifested as a probability of detection: the actual fiscal behavior of decision maker $\mathrm{i}$ will be revealed within the period with a probability of $\lambda$. This probability depends positively on the rate of the opportunistic consumption of policy maker $i$, and detection is certain after two periods:

a. $\quad \lambda_{t}=\lambda\left(C_{t, i}^{0}\right)$

(3)

b. $\quad \lambda_{t}=\lambda\left((1+r) C_{t-1, i}^{o}+C_{t, i}^{o}\right), \lambda^{\prime}>0$.

where (3a) and (3b) are the detection probabilities in the first and the second period, respectively. ${ }^{6}$ Thus, opportunistic behavior pays (at most) for the duration of two periods.

6 Note that the detection probability raises over time. The assumption that detection is certain after two periods is done to simplify notation. Our analysis can be readily extended to the case where there is no truncation of the horizon of the opportunistic decision makers. This will be the case where the detection probability 
The realized public debt is the outcome of the behavior of all the decision makers:

(4) $b_{\mathrm{i}}^{\mathrm{a}}=\mathrm{b}_{\mathrm{i}}^{\mathrm{p}}+\sum_{\mathrm{i}=1}^{\mathrm{n}} \mathrm{C}_{\mathrm{i}, \mathrm{i}}^{\mathrm{i}}$

Its value is revealed at the end of period $t$, and the public uses it as an indicator regarding the competence of the administration. A higher value of the public debt implies that a greater portion of the tax revenue will be used to service the public debt, and hence less tax revenue will be available for fiscal activities (either for the provision of public goods or for public investment). Hence, a higher fiscal deficit is viewed as undesirable by the public, reducing the survival of the administration from period $t$ to period $t+1$.

We denote by $\phi_{t+1}$ the survival probability of period t's administration to period $t+1$, and assume that $\phi_{t+1}=\phi\left(b_{l}^{a}\right)$, where $\phi^{\prime}(0)=0, \phi^{\prime}<0$ and $\phi^{\prime \prime}<0$ for $b_{t}^{a}>0$. If the administration is removed from office at the end of period $t$, it is replaced by a new one. ${ }^{7}$ We assume the absence of reputation effects, and thus all

at period $t+j$ is a function $\lambda($ ) of the net present value of all the opportunistic spending (discounted to period $t+j$ ). All the key results can be shown to apply to this modified case.

7 We assume that the election of a new administration implies the removal of all the preceding policy makers. Our analysis continues to apply for the cases where each policy maker $i$ faces independent election, and his reelection probability is $\phi_{i}$. If the repayment of the outstanding public debt is shared equally among the voters, the reelection probability of decision maker $\mathrm{i}$ will be adversely affected by the aggregate public debt, and positively related to the realized fiscal consumption in state (or province) i. Hence, in this case 
administrations and decision makers are alike. The representative decision maker (indexed by i) is maximizing his expected utility from his fiscal expenditure, given by:

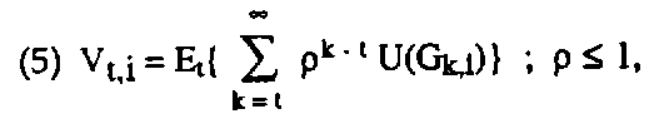

and $E_{t}$ denotes the expectation operator, based upon the information available at period $t$, and $U$ is the period utility function, satisfying $U^{\prime}>0$ and $U^{\prime \prime}<0$, and $U=0$ if the policy maker is out of office. The administration is setting policies in order to maximize the expected utility of the representative decision maker, taking into account the behavior of the atomistic decision maker as a feasibility constraint on the set of policies.

\subsection{The timing of events}

At the beginning of period $t$ the administration determines the planned allocation to the various states, $\bar{G}_{t, i}$. This decision is equivalent to the determination of the planned public debt, $b_{t}^{p}$ (note that the tax revenue $T$ is exogenously given). Next, decision makers are determining their actual use of resources, $G_{t, i}$. The actual fiscal behavior of decision maker $i$ will be revealed within the period with a probability of $\lambda$. Decision makers that are detected abusing the planned allocation will be removed from office. ${ }^{8}$ At the end of the period the actual aggregate deficit $b_{t}^{a}$ is revealed. Elections are taking place in between the two

$\phi_{\mathrm{i}}=\phi_{(}\left(\mathrm{C}_{\mathrm{t}, \mathrm{i}}^{\mathrm{O}}, \mathrm{b}_{\mathrm{t}}^{\mathrm{a}}\right) ;$ with $\partial \phi_{\mathrm{i}} \partial \mathrm{C}_{\mathrm{t}, \mathrm{i}}^{\mathrm{O}}>0$ and $\partial \phi_{\mathrm{i}} \partial \mathrm{b}_{\mathrm{t}}^{\mathrm{a}}<0$. It can be verified that the key results of our paper continue to apply in this modified structure.

8 Detection and removal from office implies that the decision maker's utility at that period is normalized to zero. We assume that detection occurs after the commitment of resources, hence it does not impact the aggregate actual public debt. 
periods, and the present administration is reelected with probability $\phi_{t+1} \cdot{ }^{9}$ The elected administration starts its tenure at the beginning of period $t+1$.

\section{Equilibrium and tacit cooperation}

We turn now to characterize the equilibrium in several steps: First, we analyze the conditions determining the behavior of a policy maker who behaves opportunistically. Next, we analyze the incentive constraints imposed by the opportunistic policy makers on the behavior of the administration. Finally, we apply these constraints to characterize the factors determining the degree of cooperation achieved via tacit cooperation.

Formally, our framework is a repeated game, in which a one-period simultaneous move game is repeated each period. 10 At each date $t$, players know all the moves before $t$. As is usual in this context, multiple equilibria are sustainable with the appropriate punishment. Following the literature, we focus on the symmetric, efficient equilibrium from the players' viewpoint. For a given planned deficit we derive the optimal behavior of each decision maker. Sequential rationality and efficiency will be shown to require the administration to choose the public debt that maximizes the welfare of the representative decision maker subject to a feasibility constraint. The planned public debt rate must be chosen so as to prevent the opportunistic behavior of the atomistic decision makers.

9 Recall that we assume that detection is certain after two periods. Hence, in between period $t$ and $t+1$ any remaining decision makers that abused their budget constraints in period $t-1$ are removed from office.

10 For a review of repeated games and tacit cooperation see Tirole (1988). 
We turn now to evaluate the behavior of the opportunistic decision maker in his first period in office. A policy maker that chooses to behave opportunistically at period $t$ knows that he is out of his office within not more than two periods. Applying (2), (3), and (5) we conclude that he sets $C_{\mathrm{t}, \mathrm{i}}^{0}$ in order to maximize his expected utility at time $t$ (denoted by $\left.V_{t}\right|_{0}$ ):

$$
V_{t} l_{o}=\left(1-\lambda_{d}\right)\left[U\left(G_{t, i}\right)+\rho \phi_{t+1}\left(1-\lambda_{t+1}\right) U\left(G_{t, i+1}\right)\right]
$$

yielding the following first-order condition:

$$
\text { (7) } \quad \frac{\partial V_{1} 0}{\partial C_{t, i}^{0}}=0
$$

where MUdo stands for the marginal utility at date $t$, evaluated at the opporturistic level of consumption.11 The optimal opportunistic consumption equates the marginal benefit attributed to more resources obtained with the marginal cost generated by the higher probability of detection.

We turn now to characterize the cooperative regime. The expected utility attained with cooperation is denoted by $\mathrm{VI}_{\mathrm{C}}$, where

$$
\left.V_{t} l_{c}=U\left(\bar{G}_{t, i}\right)+\sum_{k=t+1}^{\infty} \rho^{k-4} \prod_{j=t+1}^{k} \phi_{j}\right] U\left(\bar{G}_{k, i}\right)
$$

Alternatively,

$$
V_{t} l_{c}=U\left(\bar{G}_{t, i}\right)+\rho \phi_{t+1} V_{t+1} l_{c}
$$

11 The condition is that

$$
\begin{aligned}
& \left(1-\lambda_{J}\right) M U^{\prime l o}=\lambda\left[U\left(G_{t, i}\right)+\rho \phi_{t+1}\left(1-\lambda_{t+1}\right) U\left(G_{t, i+1}\right)\right]+\lambda_{t+1}^{\prime} \rho(1+r) \phi_{t+1}\left(1-\lambda_{J}\right) U\left(G_{t, i+1}\right)+ \\
& \left.\left(1-\lambda_{J}\right) \rho\left(1-\lambda_{t+1}\right)\left\{\frac{(1+r) \phi_{t+1} M U_{t+1} l_{0}}{n}-\dot{\phi}_{t+1}\right) U\left(G_{t, i+1}\right)\right\} \text {. }
\end{aligned}
$$

The assumption that detection is certain after two periods implies that the condition determining $C_{t+1, i}^{0}$ is $\left(1-\lambda_{t+1}\right) M U_{t+1} l_{0}=\dot{\lambda}_{t+t} U\left(G_{t+1, i}\right)$. 
We now evaluate the public debt policy implemented by the authorities. Applying (8) it follows that

$$
\frac{\partial V_{I_{c}}}{\partial b_{t}^{P}}=\frac{M U_{l} l_{c}-\rho(1+r) \phi_{t+1} M U_{t+1} l_{c}}{n}+\dot{\phi_{t+1}} \rho V_{t+1} I_{c}
$$

Starting with zero public debt, the expected utility in the cooperative equilibrium will tend to rise with the public debt (recall that $\phi^{\prime}(0)=0$ ). 12 As we increase the public debt, the marginal benefit of the debt is eroded, while the cost (in terms of reducing the reelection probability) goes up. Hence, for a large enough public debt the expected utility in the cooperative regime will start declining with future increase in the public debt. The optimal public debt in a cooperative regime (denoted by $b_{t}^{P} l_{c}$ ) is determined by the condition that $\frac{\partial V_{t} l_{c}}{\partial b_{t}^{P}}=0$ : it balances the marginal value of resources achieved by higher public debt with the marginal cost resultant from the drop in the administration's probability of survival and the higher future repayment. Figure 1 summarizes the possible regimes. Curve CC describes the expected utility obtained by cooperation, drawn against $\mathbf{b}_{\mathbf{t}}^{\mathbf{p}}$. The bliss point achieved in the cooperative regime with the optimal public debt is denoted by co.

12 A sufficient condition assuring this for the case where $p=1 /(1+r)$ is that the inherited public debt is positive, or that $\phi(0)<1$ (i.e., the reelection probability is less than one). 


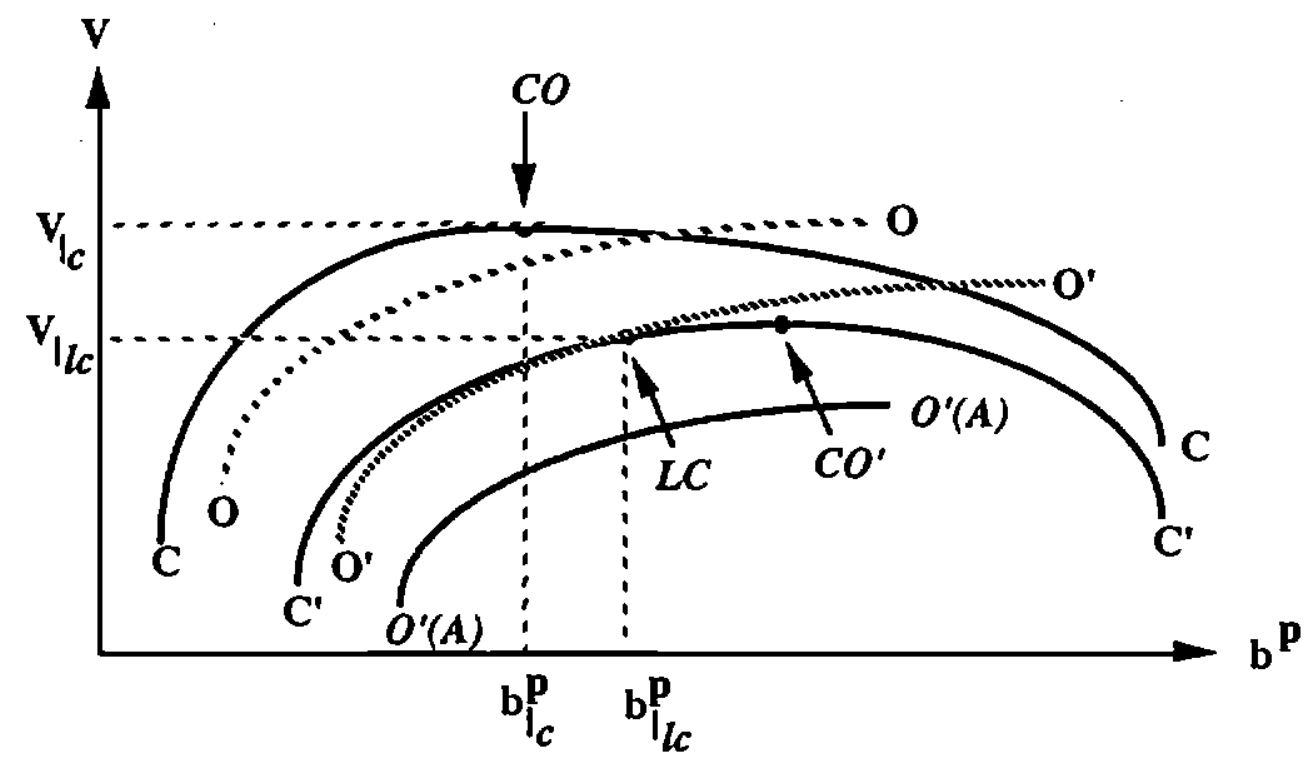

Figure 1

We turn now to characterize the opportunistic regime. Applying (6) we infer that a higher planned public debt affects $\mathrm{V} \mathrm{l}_{\mathrm{O}}$ by:

$$
\frac{\partial V_{t} l_{0}}{\partial b_{t}^{p}}=\left(1-\lambda_{t}\right)\left[\frac{M U_{t} I_{0}-p(1+r) \phi_{t+1}\left(1-\lambda_{t+1}\right) M U_{t+1} I_{0}}{n}+\dot{\phi}_{t+1} \rho\left(1-\lambda_{t+1}\right) U\left(G_{t, i+1}\right)\right]
$$

Similarly to the cooperative regime, starting with zero public debt the expected utility of the opportunistic decision maker will tend to rise with the public debt (recall that $\phi^{\prime}(0)=0$ ). As we increase the public debt, the marginal benefit of the debt is eroded, while the cost (in terms of reducing the reelection probability) goes up. In comparison to the cooperative regime, however, a higher public debt induces smaller costs for the opportunistic decision maker, as he attaches a lower weight to 
the future. ${ }^{13}$ Hence, the presumption is that at the cooperative optimal public debt (point $\mathrm{CO}$ ) a higher public debt is desirable for the opportunistic decision maker. ${ }^{14}$ Curves $O$ and $O^{\prime}$ describe two possible locations of the expected utility generated by the opportunistic behavior, drawn against $b_{t}^{p}$.

If the opportunistic expected utility, at the optimal cooperative pubic debt, is lower than the expected utility from cooperation, then we will observe cooperation. In terms of Figure 1, this will happen if curve $O$ is below curve $C$ at the cooperative optimal public debt, leading to a cooperative equilibrium at point $C O$, where the public debt is at the level that maximizes the cooperative expected utility. If the opportunistic utility is higher than the one achieved with cooperation at $\bar{b}_{\mathrm{l}} \mid c$, cooperation is not self sustained, and equilibrium will occur at a lower public debt.

For example, suppose that the opportunistic and cooperative expected utility schedules are given by $\mathrm{O}^{\prime}$ and $\mathrm{C}^{\prime} .15$ Note that the cooperative equilibrium is reached now at point $\mathrm{CO}^{\circ}$, and is not sustainable, because all decision makers will behave opportunistically. The resultant equilibrium must yield an expected utility

13 The costs of higher public debt stem from the lower probability of reelection, and lower net resources in the next period (when repayment is due). The lower probability of survival of the opportunistic decision maker (relative to a decision maker who behaves cooperatively) implies that the expected cost of a higher public debt tends to be lower for him.

14 A sufficient condition for this is a large enough $\lambda_{1+1}$.

15 The existence of such a situation can be verified by noting that a smaller value of $\lambda$ will shift the $O$ curve upwards. For a value of $\lambda$ close enough to zero decision makers behave opportunistically at the cooperative equilibrium. 
that is below the optimal cooperative utility, on curve $O^{\prime}(A) .16$ The sustainable equilibrium is characterized by the highest cooperative expected utility that does not lead to deviations (and thus $\mathrm{VI}_{\mathrm{o}} \leq \mathrm{VI}_{\mathrm{C}}$ ), at a point like $L C$, where curve $\mathrm{O}^{\prime}$ intersects with $C^{\prime}$. We denote the corresponding public debt by $b_{t}^{p}{ }_{t c^{\prime}}$ and refer to it as the limited-cooperation public debt. This public debt is self-sustained as no benefits are obtained by the opportunistic behavior. The administration does not reduce the public debt below $b_{t l l c}^{p_{c}}$, as this will reduce expected utility; and it cannot push it above, due to the presence of opportunistic behavior.

We turn now to evaluate the conditions that may induce an economy to switch from cooperation to an equilibrium where cooperation is limited. Suppose that the relevant curves in the initial equilibrium are $C C$ and $O O$, and hence the equilibrium is at point $\mathrm{CO}$, corresponding to the cooperative regime. Let us consider the impact of an adverse shock, like a transitory drop in taxes. For a given $b_{t}^{p}$, an adverse fiscal shock will shift curves $O$ and $C$ vertically by $\left(1-\lambda_{l}\right)\left[M_{t} l_{0}\right] \frac{\Delta T}{\Omega}$ and $\left[\mathrm{MU}_{\mathrm{l}} \mathrm{l}_{\mathrm{C}}\right]_{\mathrm{n}} \mathrm{T}$, respectively. Recall that $\mathrm{GI}_{\mathrm{O}}>\mathrm{GI}_{\mathrm{C}}$, and thus $\mathrm{MU}_{\mathrm{O}}<\mathrm{MU}_{\mathrm{C}}$. Consequently: for $\left.\Delta T<0 ;\left[M U_{d}\right]_{C}\right] \frac{\Delta T}{\Omega}<\left(1-\lambda_{t}\right)\left[M_{\mathrm{l}} b\right] \frac{\Delta T}{n}<0$. The drop is greater for the utility in the cooperative regime. This follows from two reasons. Recall that the pattern of consumption is front-loaded in the opportunistic regime, relative to the cooperative one. The principle of diminishing marginal utility implies that a drop in income equal in both regimes will induce a smaller drop in the expected utility associated with the opportunistic regime, as this regime is associated with a higher contemporaneous consumption. In addition, the probability of detection under the opportunistic regime reduces the weight attached to the marginal loss in that

16 Note that if all decision makers behave opportunistically, $\phi$ drops considerably, reducing the realized expected utility. Thus, curve $O^{\prime}(A)$ is defined by (6), for the case where $b_{t}^{a}=b_{t}^{p}+n C_{t, i}^{o}$. 
regime, relative to the cooperative one. If we started with cooperation at a point like $\mathrm{CO}$, the likelihood of cooperation diminishes. If the adverse shock is large enough, we may end up with limited cooperation, at a point like $L C$. Thus, we conclude that willingness to cooperate among policy makers is in short supply when times are bad. Our analysis can be readily extended to account for the effects of permanent shocks, where the impact of a permanent drop in taxes is qualitatively similar, but stronger, than the impact of a transitory drop. ${ }^{17}$

We turn now to evaluate the impact of transitory shocks on the optimal public debt. Suppose that there is a transitory drop of taxes. In the cooperative regime, it follows from (9) that: 18

$$
\text { (11) }-1<\frac{d\left[b_{t}^{P} l_{c}\right]}{d T}<0
$$

The public debt is used to smooth the fiscal consumption throughout the business cycle, in line with the standard predictions of optimizing macroeconomic models. In the regime with limited cooperation, however, the behavior of the public debt is determined not by the 'first-best' economic considerations described above. Instead, the dynamics of the public debt are determined by the binding incentive constraint -preventing opportunistic behavior dictates the pattern of debt. To verify this point, note first that in the vicinity of the limited cooperative equilibrium, curve $C^{\prime}$ must be flatter than curve $O^{\prime}$ (otherwise everyone will be better off by increasing the

17 In this case curves $O$ and $C$ drops vertically by $\left(1-\lambda_{t}\left[\left(M U_{t} l_{0}+\rho \phi_{t+1}\left(1-\lambda_{t+1}\right) M U_{t+1} l_{0}\right] \frac{\Delta T}{n}\right.\right.$ and $\left[M U_{i l}+\rho \phi_{t+1} M U_{t+1} l_{C}+\ldots\right] \frac{\Delta T}{n}$, respectively.

18 It can be verified that

$$
\frac{d\left[b_{t}^{p} l_{c}\right]}{d T}=-\frac{\left[M U_{t}^{\prime} l_{c}\right)\left(n^{2}\right)}{\partial^{2}\left[V_{t} l_{c} V d b_{t}^{p}\right]^{2}}=-\frac{\left[M U_{t}^{\prime} l_{c}\right]\left(n^{2}\right)}{\frac{M U_{t}^{\prime} l_{c}+\rho(1+r)^{2} \phi_{t+1} M U_{t+1}^{\prime} l_{c}}{n^{2}}+\phi_{t+1}^{n} \rho V_{t+1} l_{c}}>-1
$$


public debt). Formally, defining $D$ by $D=V I_{0}-V I_{c}$, at $b_{t}^{p}=b_{t}^{p} l c c=0$ and $\frac{\partial D}{\partial b_{t}^{p}}>0$. Applying this information we infer that

$$
\frac{d\left[b_{l}^{p} l_{c c}\right]}{d T}=\frac{\left[M U_{t} l_{c}-\left(1-\lambda_{v}\right) M U_{t} l_{0}\right]_{n}}{\partial D / \partial b_{t}^{p}}>0 ;
$$

Further insight may be obtained by referring to Figure 1. Suppose that prior to the shock the relevant curves are $\mathrm{CC}$ and $O O$, and hence the equilibrium is at point $\mathrm{CO}$, corresponding to the cooperative regime. The adverse shock shifts both curves down, but the shift of curve $C C$ is larger. In terms of Figure 1, $C C$ shifts to $\mathrm{C}^{\prime} \mathrm{C}^{\prime}$, such that the desirable cooperative equilibrium calls for a higher public debt, moving to point $\mathrm{CO}^{\prime}$ (as is implied by (11)). If the shock is large, we may end up with $\mathrm{O}^{\prime} \mathrm{O}^{\prime}$ above $\mathrm{C}^{\prime} \mathrm{C}^{\prime}$ at the cooperative bliss point, as is drawn in Figure 1. In this case, the ultimate equilibrium is at point $L C$, due to the constraints imposed by the opportunistic behavior. The adjustment from the previous to the new equilibrium can be broken into two parts: moving from $\mathrm{CO}$ to $\mathrm{CO}^{\prime}$, reflecting the adjustment within the cooperative regime, and the shift from $\mathrm{CO}$ to $\mathrm{LC}$, reflecting the regime switch. Note also that the regime switch is associated with a drop in the public debt, needed to avoid the opportunistic outcome (i.e., the public debt is lower at LC relative to $\mathrm{CO}^{\prime}$ ). Furthermore, when we operate in the regime associated with limited cooperation, further adverse shocks will force a drop in the public debt, needed to sustain the limited cooperation, preventing the switch to a noncooperative outcome.

If the shock is large enough, the drop in CC may be large enough that the new $\mathrm{CC}$ and $\mathrm{OO}$ do not share any points. In this case limited cooperation is not achievable -- the noncooperative forces are powerful enough to prevent the 
attainment of limited cooperation. In terms of Figure 1, this will imply that we end up on curve $O^{\prime}(A)$. This is the case where the absence of cooperation releases powerful negative externalities: each policy maker ignores the adverse effect of opportunistic expenditure on the survival probability of all other decision makers, ending up with an inefficient outcome, shortening the political horizon of all policy makers. This is the stage where the resolution of the crisis may require fiscal reform, shifting more power to the center, and tightening the monitoring of the various decision makers.

The regime switch may yield nonlinearities, where the macroeconomic behavior is abruptly altered following the regime switch, which in turn will occur if the severity of adverse shocks reaches a certain threshold. In terms of equation (12), note that $\partial D / \partial b_{t}^{p} \rightarrow 0$ as we approach the switch from limited cooperation to the noncooperative regime. Consequently, the sensitivity of the macroeconomic variables (for instance, to public debt) to shocks increases sharply, and with regime switch we may observe discontinuity in the patterns of public debt. Figure 2 describes the dependency of public debt on the tax at time $t$, where regions co, lc and nc correspond to the cooperative, limited cooperation and the noncooperative regimes. 19

19 Note that the switch to the noncooperative regime entails a change in the administration's operation. It will set the planned public debt at the level that maximizes the expected utility along curve $O^{\prime}(A)$. 


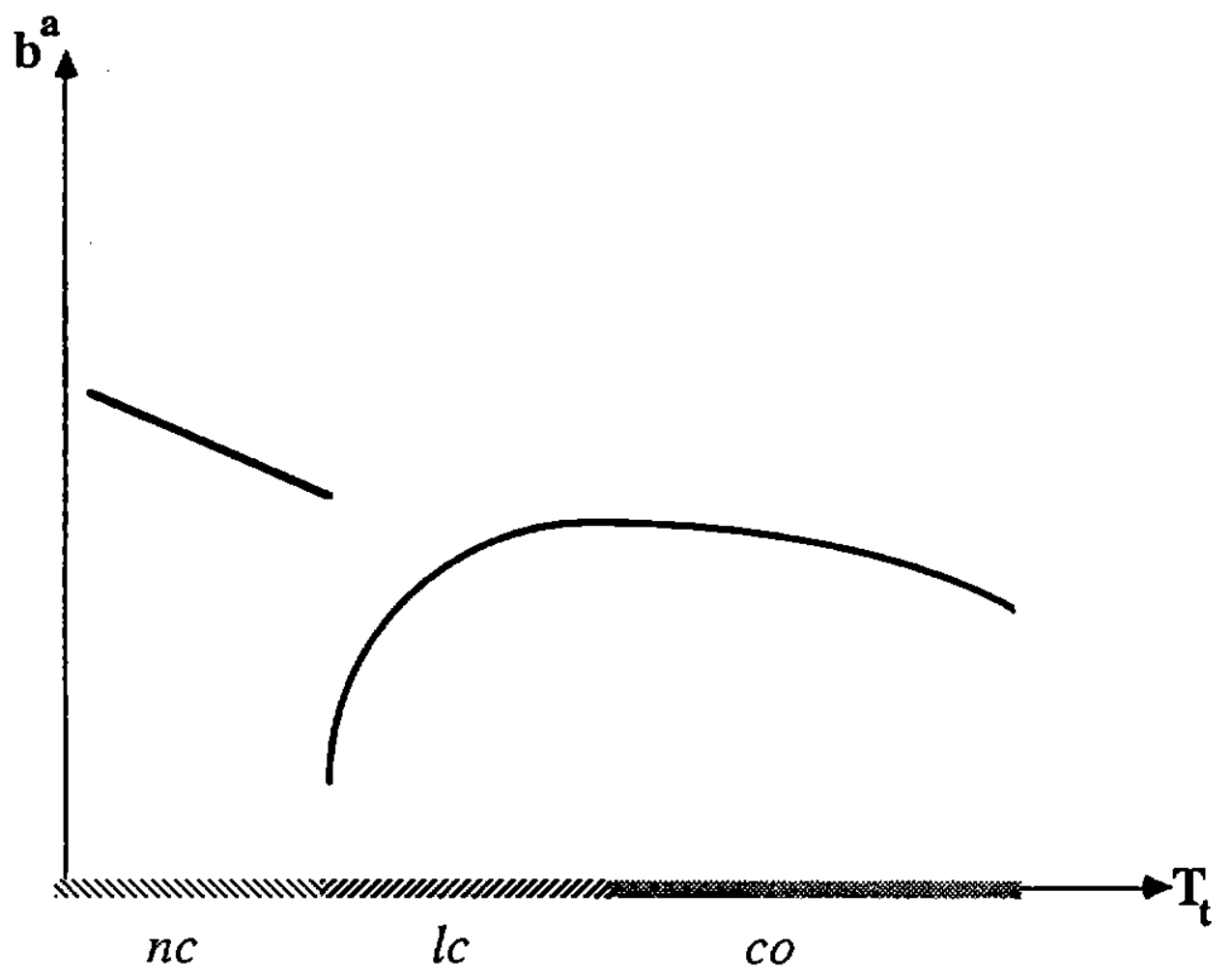

FIGURE 2

Applying the above analysis, it follows that a large inherited public debt will tie the hands of the policy makers, preventing them from using debt finance to cushion adverse shocks. Let us denote by $\Pi$ the net resources available to the administration in the absence of borrowing, $\Pi_{t}=T_{t}-(1+r) b_{t-1}^{a}$. Let $\tilde{\Pi}$ stand for the threshold level of net resources that induces the opportunistic behavior of decision makers. ${ }^{20}$ A cooperative equilibrium is sustainable as long as the realized tax

20 The value of $\tilde{\Pi}$ is defined in the following way. The reduced form of the expected utility of decision maker $i$ depends on three factors: the net resources 
revenue $T$ exceeds $\tilde{\Pi}+(1+r) b_{-1}^{a}$. A larger public debt increases the threshold of tax revenue needed to sustain cooperation. Alternatively, it increases the chances that the economy will switch to a regime where cooperation is limited (or to the noncooperative regime), and where the public debt cannot be used effectively to smooth public expenditure and public investment throughout recessions. 21 Hence, limits to public debt free the instrument of public debt to serve its traditional role.

available to the administration, the planned public debt, and the degree of cooperation. Let $V_{k}\left(b_{t}{ }_{t} ; \Pi_{t}\right)$ denote the expected utility of a decision maker for $a$ planned public debt $b_{t}^{p}$ and net resources $\Pi_{t}$ in regime $k, k=c$ or $o$. The cooperative equilibrium is sustainable only if $V_{o}\left(b_{t}^{p_{i}} ; \pi_{t}\right) \leq V_{c}\left(b_{i}^{p} ; \pi_{t}\right)$. We define $\tilde{\Pi}$ as the lowest net resources under which cooperation is sustainable: $V l_{0}\left(b_{t}^{p} ; \tilde{n}_{t}\right)=V l_{c}\left(b_{t}^{p} ; \tilde{n}_{t}\right)$. In terms of Figure 1 , at $\Pi=\tilde{\Pi}$ the corresponding $O O$ curve intersects the $C C$ curve at the cooperative bliss point (hence points $C O$ and LC coincide). Thus, for $\Pi_{t}<\tilde{\Pi}_{t}$ cooperation is not sustainable, and we operate in the lc regime.

21 This argument can be illustrated using Figure 2. A higher outstanding public debt $\left((1+r) b_{-1}^{a}\right)$ shifts the curve to the right, enlarging the range of the noncooperative regime, and increasing the threshold level of taxes needed to sustain cooperation. 


\section{Concluding Remarks}

The above analysis pointed out that recessions (or lack of growth in the economy) will reduce the degree of cooperation among policy makers. In the context of fiscal expenditure, bad times may force policy makers to scale down the public debt (or to expend it at a lower rate, relative to the first best, cooperative outcome), exacerbating thereby the recession. Minimizing the prospects of this scenario requires limiting the public debt in good times. While our discussion was framed in a nonstochastic framework, it suggests that the public debt ceiling may be related to the volatility of the shocks. Higher volatility of productivity shocks calls for a lower limit on the allowed public debt, as the chance of switching to the noncooperative regime goes up. Hence, the desirable public debt limit may be a moving target that is adjusted to reflect expectations regarding the volatility of future shocks.

A limitation of this analysis is that in practice there exists a wide spectrum of financial arrangements between the peripheries and the center that may modify the operation of these externalities. The message of this paper holds, however, as long as these financial arrangements do not entirely curb the incentive to shift expenditure from the peripheries to the center. For example, in Europe each country may finance its own public debt issuing country-specific bonds. This arrangement by itself does not negate the potential operation of the externalities discussed above. The logic of our analysis prevails even if each union member has its own debt, as long as there are some states of nature where the union members can shift some of the financing of their expenditure to the center. 


\section{REFERENCES}

Aizenman, J. (1992) "Competitive Externalities and the Optimal Seigniorage," Journal of Money, Credit and Banking 24, 61 - 71 .

(1993) "Soft Budget Constraints, taxes and the incentive to cooperate," International Economic Review, 819 - 832.

Alesina, A. and Drazen, A. (1991) "Why Are Stabilizations Delayed?", American Economic Review (December), 1170-88.

Bryant J. (1985) "Analyzing Deficit Finance in a Regime of Unbacked Government Paper," Economic Review, Federal Bank of Dallas 15, 17-27.

Buiter W. H. and R. C. Marston, eds. ( 1985) International Economic Policy Coordination, (New York: Cambridge University press).

Canzoneri, B. M. (1989) "Adverse Incentives in the Taxation of Foreigners", Lournal of International Economics $27,283-97$.

and Gray, I. A. (1985) "Monetary Policy Games and the

Consequences of Non-cooperative Behavior," International Economic Review 26, 547 - 64 .

Casella A. (1991) "Participation in a Currency Union," American Economic Review, 81, pp. $847-863$.

Cukierman, A., Central Bank Strategy. Credibility and Independence: Theory and Evidence, Cambridge, MA: The MIT Press, 1992.

De Grauwe P. (1992) "The Economics of Monetary Integration", Oxford University Press.

Hamada, K. (1976) "A Strategic Analysis of Monetary Interdependency," Lournal of Political Economy 84, 677-700.

Persson, T. and G. Tabellini. (1990) "Macroeconomic Policy, Credibility and Politics," (Harwood Academic Press, Chur, Switzerland). 
Rogoff, K. S. (1989) "Reputation, Coordination and Monetary Policy." In Modern Business Cycle Theory edited by R. J. Barro, (Harvard Press).

Tornell A. and A. Velasco. (1992) "The Tragedy of the Commons and Economic Growth: Why Does Capital Flow From Poor to Rich Countries? Journal of Political Economy, Vol. 100, December .

Turnovsky S. J., Tamer B. and V. D'orey. (1989) "Dynamic Strategic Monetary policies and Coordination in Interdependent Economies," American Economic Review 78, 341-361.

World Bank, Argentina: Provincial_Government Finance (Washington, The World Bank, 1990).

Wyplosz, C. (1991) "Monetary Union and Fiscal Policy Discipline," EC Commission, European Economy, Special Edition, 1. 